\title{
The Acceptance and Practice of Citizen Journalism in The North Eastern Part of Nigeria
}

\author{
Oberiri Destiny Apuke \\ Taraba State University, Nigeria \\ apukedestiny@gmail.com \\ Livinus Jesse Ayih \\ Taraba State University, Nigeria \\ livinusayih@gmail.com
}

\begin{abstract}
This study aimed at increasing our understanding of citizen journalism practice, with a focus on rural dwellers which has been less well studied. This study, which is anchored on democratic participant media theory took place at Ardo Kola, Taraba State in the north-eastern region of Nigeria. The data were collected through face-to-face semi-structured interviews, among 40 rural dwellers. The findings confirmed acceptance and knowledge of citizen journalism among the rural dwellers, but its adoption and practice are still very minimal due to poverty, power failure, their attitude, religious upbringing, customs, high level of illiteracy, high internet subscription and slow speed. It was suggested that government should make efforts to set up good schools, create more job opportunities, sponsor the skill work of those who did not attend formal education, and improve power supply in the rural communities. Interestingly, it was found among many other things that citizen journalism provides an avenue for community dwellers to gather and disseminate messages with immediacy, assists in the checkmating of the excesses of government officials, and promotes a healthy lifestyle in community settings. Therefore, it is relevant to encourage citizen journalism practice in rural areas, and further studies could explore beyond the use of a single community, more issues confronting rural dwellers as regards the adoption and practice of citizen journalism in developing countries.
\end{abstract}

Keywords: Citizen journalism, community, Nigeria, democratic participant media theory, rural dwellers

\section{INTRODUCTION}

The progress of the cyberspace and other new technology devices has resulted in a new course where people cover events and distribute content easily and directly. Thus, the advent of the new media has introduced the concept of citizen journalism, which is the act of allowing ordinary individuals to play an active role in the process of collecting, reporting, analysing 
and disseminating news and information to the public (Paulussen \& Ugille, 2008). This suggests journalism that makes everybody the source and the receiver; the encoder and the decoder at the same time (Salawu, 2011). No wonder, Bowman and Willis (2003) referred to it as the We Media. Elaborating on this notion, Apuke (2016) view "citizen journalist" as an individual, who is not a disciplined professional, but nonetheless may report on his or her neighbourhood or residential district. Therefore, the development of mobile devices, social networks, micro-blogging and other digital tools have permitted people to publish their own stories and cover their own communities, in turn reducing the monopoly of information gathering and dispersal from the conventional media to a more interactive media environment (Tsegyu, 2016). This implies that people can now consume media as desired and needed rather than allowing media producers to schedule consumption time and content. This benefit has made it possible for citizen journalism to gain some acceptance in the Nigerian context. There is evidence to indicate that in Nigeria, a considerable amount of people are now actively participating in citizen journalism; developing different websites and blogs to distribute information. Dare (2011: 22) observed that Odili.net has been in existence since 2002, others are the Nigerian Village Square (NVS) established in 2003 and the Nairaland, in 2004 which was named after the Nigerian currency. Other online media websites include Africa.net, Sahara Reporters, Naija Community, and Naijapals.com among others, which suggests the progress of citizen journalism in Nigeria.

Research has proven that the effectiveness of citizen journalism has been examined. For example, the roles of citizen journalism in the Arab uprising popularly known as the Arab Spring and the Occupy Movement in the United States of America is inevitable. Specifically, in Nigeria, citizen journalism played a substantial role in the nationwide protest against fuel subsidy removal in 2012 (Odii, 2013). This indicates the relevance of citizen journalism in our contemporary times (Noor, 2017), suggesting that anyone can be a citizen journalist since the Internet and new media technologies offer unlimited opportunities to upload and share content for public consumption. In this regard, evidence has shown that citizen journalism has been widely criticised by its opponents as amateurish, misleading, fallacious, subjective in quality and coverage. Some critics claim that veracity is murdered in citizen journalism. Thus, its practice is believed to be characterized by the issues of trust, credibility, and lack of objectivity and balance. Grubisich (2005) in his review of ten new citizen journalism sites found that many of them are lacking in quality and content. Undoubtedly, citizen journalism has attracted mixed reactions, while the proponents say that it is good for the society, the opponents hold that it is injurious to the peaceful existence and governance of the society.

This notion calls for more studies to explore elaborately the phenomenon of citizen journalism. Some of the studies (e.g. Salawu, 2011; Noor, 2017) that have probed into citizen journalism practice in Nigeria are still far from adequate, and due to its contentious nature, it is pertinent to explore further the prospects and constraints of citizen journalism adoption and practice in a developing country such as Nigeria. There has been a strong focus for understanding the subject matter from professional media practitioners and urban dwellers with a less focus on rural areas (Aligwe \& Nwafor, 2017; Odii, 2013). Therefore, understanding the phenomenon of citizen journalism from the rural public lens will advance our understanding as regards citizen journalism in a developing country like Nigeria as well as demonstrate ways in which the practice could be improved. The outcomes of this study are beneficial to the eclectic growing body of studies on alternative, participatory, community and citizen journalism. 


\section{AIM AND OBJECTIVES}

The main thrust of this study is to ascertain the prospects and constraints of citizen journalism practice in rural communities in Nigeria, with a focus on Ardo Kola in the north-eastern Nigeria. To accomplish this purpose, this article is guided by the following objectives:

- To confirm whether rural dwellers entirely accept and participate in the exercise of citizen journalism.

- To recognise the prospects of citizen journalism in rural communities.

- To find out the constraints of adopting citizen journalism in rural communities.

- To establish ways in which citizen journalism practice could be better encouraged among rural community dwellers.

\section{REVIEW OF RELATED LITERATURE}

The issues of citizen journalism in Nigeria have attracted a growing body of research with diverse results. For instance, Salawu (2011:194) observed that citizen journalism has profound implications for the blossoming of democracy. This supports Bowman and Willis (2003: 5458), that listed the benefits of citizen journalism to include an increased trust in media, shared responsibility in informing democracy, and better journalism, etc. Also, Apeverga (2010) in Idoko (2012) carried out a study on the impact of citizen journalism in Nigeria. The study revealed that citizen journalism has impacted a lot on the lives of Nigeria people and that everyone is now a reporter and has the right to air out his view without running to a media house. However, the findings of the same study established that people most times don't get the true picture of a story before posting it on the internet just because they want to be the first to post about a particular happening. Furthermore, Okoro et al. (2013) discovered that Citizen Journalism is emerging as a powerful phenomenon across Nigeria. This view is concretized by Dare (2011: 44) who found that Sahara Reporters, a citizen journalists' website was rated by 86 of the 120 respondents as a serious source of breaking news. This proposes that due to its interactivity and ability to present news in split seconds, citizen journalism has presented a severe challenge to the mainstream media in Nigeria, it has broadened people's access to a variety of news, during emergencies.

Consequently, some scholars maintained that citizen journalism is a serious sort of journalism that eradicates the top-down monopolistic communication. Annotating on the benefits of citizen journalism, Alemoh (2013) observed that most of the issues the mainstream media leave out, the citizen journalist easily captures. Events that occur in distant places are now published directly by citizen journalists; making the public to be mindful of certain matters that happen around them. For example, the plane crash that occurred on 25 October 2012, of the former and the late Governor of Taraba state of Nigeria Governor Danbaba Danfulani Suntai, was reported instantly by citizen journalists/ eyewitnesses, however; it took about 24 hours for the mainstream media houses in Nigeria to report the same story. Furthermore, most of the events of the Boko Haram bomb blast are being reported instantly by citizen journalists accompanied by photographs of the incident even before the mainstream media stations arrive destinations of the bomb attack. This suggests that citizen journalism provides an avenue for both pros and novice in the origination and airing of news content to the receiving public/audience. It has made journalism to be more democratic and participatory as opposed to the mainstream monopolistic media production. Some other interesting aspect 
of citizen journalism is its speed in delivery of the message. It delivers messages in a flash like the focal ratio of light and this is possible due to its lack of gatekeeping. It, therefore, has immediate feedback from the audience as in the case of Facebook comments and liking. That is the reason why many people call citizen journalism "we media" because of the content made by the people and for the people.

However, some other authors claim that due to its lack of credibility and authenticity of its content it is endangering the societal information cycle. In respect of this, Maher (2005) observed that the effectiveness of citizen journalism has been debunked by the mainstream media due to its lack of objectivity. Consequently, a bunch of journalist and media houses views citizen journalism with doubt and uncertainty, believing that journalism practice is intended for trained journalists who understand the objectivity and balance as well as the whole canons of journalism. Supporting this view, Mgbejume (2008) asserts that a journalist has to undergo training before he is equipped to publish effectively; he likened an untrained journalist to a madman left with a gun who can shoot at will without control which leads to disaster. As far as this author is concerned, before one publishes news online, he ought to receive journalistic training to become familiarized with the moral philosophy of the profession. In addition, Educause Learning Initiative (2007) postulates that by permitting anyone to collect and broadcast the message to the public, citizen journalism practice will be more of personal interest, myopic view and as well cultivate new media community of same interest. However, via blogs, Facebook, Twitter its citizen journalist has disseminated breakthrough information on political oppression, corruption and economic theft in the society and the world at large.

Substantiating the criticism on citizen journalism, Dare (2011: 44) reported that only 33 respondents of the 120 surveyed trusted Sahara reporters. This, suggests that some Nigerians do not believe stories from citizen journalists, because they spread falsehood. In the same manner, Apuke (2016) commented that the issue affecting citizen journalism in Nigeria is its lack of gatekeepers or editors to filter the information before it gets to the public. This suggests that citizen journalism in Nigeria might be full of duplication, malpractices, wrong misleading information. Most of the news and information passed using citizen journalism might not be genuine, they could be propaganda that is aimed at either annoying or causing anger, promoting injustice or even creating enmity among the targeted audience. This view is consistent with Okoro et al (2013) who argue that citizen journalism fuels civil unrest, political instability, and ethnoreligious crisis. In this regard, Aligwe and Nwafor (2017) in an empirical study that focused on Citizen Journalism and the coverage of the 2015 General Elections in South-East Nigeria, identified a lack of professionalism, credibility question, over sensationalism, the anonymity of sources and difficulty in regulation as some of the major weaknesses of the practice. This notion is in harmony with prior research by Chatora (2012) which suggests that the practice of citizen journalism during the Nigerian 2011 general elections did the nation greater harm than good as it provided a venue to disseminate provocative and insulting messages that eventually precipitated the post-election violence and tensions witnessed in many parts of the country, especially the north which is the epicentre of bloodletting.

The problem affecting the effectiveness of citizen journalism in Nigeria has also been outlined by some authors. For example, Idoko (2012) discovered the challenges of citizen journalism in Nigeria to include; computer illiteracy, difficulty in accessing the internet and high price of 'surfing' the net. This means that the high cost of internet subscription 
impedes the effectiveness of citizen journalism in Nigeria. Due to the lack of free internet service, anyone who desires to post any event online must buy "data" which is expensive to some due to the economic situation. Even so, the author found out the benefits of citizen journalism cannot be cast out. These include wider coverage of events, urgency in media reports and encouragement of information and communication technology (ICT) in the country. Another impediment to citizen journalism in Nigeria is the high level of illiteracy in the country. According to the World Development Indicators (2010), adult literacy level in Nigeria is $60 \%$. This means that $40 \%$ of the population (about 60 million people in Nigeria) is excluded from citizen journalism and all other opportunities for audience participation that may require basic literacy (UNDP, 2010: 69). This is dangerous to the health of the nation's democracy and a strong bane to citizen journalism in Nigeria. Aligwe and Nwafor (2017) survey found uneven penetration, illiteracy, constant power failure, endemic poverty and systemic corruption as the major threats affecting the effectiveness of citizen journalism in Nigeria. The authors recommend more efforts to enhance even penetration of ICTs in the country and address the issue of systemic corruption and endemic poverty, as these have continually constituted a major setback to every aspect of her development.

\section{THEORETICAL UNDERPINNING}

This paper is anchored on the democratic participant media theory which examines the role citizens play in gathering and disseminating information in a society. The democratic participant media theory was developed by Dennis McQuail during the '80s. According to Folarin (1998: 29-30), the theory discards the top-down communication system that involves professionals and commercial driven motive operators who hijack the media for their selfish interest but agitate for pluralizing and democratize form of access and production of media contents. The theory advocates that media content generation, production, and dissemination should be done by one person to another instead of concentrating on particular top groups. It calls for the media to be a medium of the people, for the people and by the people rather than a medium in the hands of a few monopolistic groups. Ojobor (2002: 15) states that this theory advocates for more horizontal rather than vertical (top-down) communication, due to the continued commercialization and monopolization of the media stations as well as centralism of public broadcast stations. Corroborating this view, McQuail (1987: 123) noted that one of the basic principles of the theory is that "individual citizens and minority groups have rights to access the media (rights to communicate) and rights to be served by the media according to their own determination of need. Therefore, this theory advocates for the liberalization of the media for the common good of the people it is meant to serve. It suggests that people should have free access to the means of communication as against the monopolistic and rigid structure of traditional mass media. This theory is applicable to this current research because it focuses on the citizens' participation in information gathering and dissemination. Thus, the theory supports participatory, citizen and alternative journalism, which this present work attempts to investigate in the Nigerian context.

From the literature reviewed, it could be deduced that the issues of citizen journalism in Nigeria has been less well studied even though the knowledge of its practice seems to be prevalent among some citizens, yet, the literature is growing. It was also observed that most of the reviewed papers are still far from adequate due to their surface technique of examining the subject matter. Most of the studies depended on a survey questionnaire 
method with a strong focus on understanding the phenomenon of citizen journalism from mostly the professional media personnel's, and urban dwellers with less emphasis on the rural public/dwellers (Odii, 2013). It is, therefore, worthwhile to study the phenomenon of citizen journalism through the rural dwellers lens since it mostly referred to journalism for the common man/citizen or community. This current study will, therefore, contribute to the body of knowledge by researching (using an interview method) citizen journalism practice among the rural dwellers and community. It will attempt to understand the prospects and constraints of citizen journalism practice in rural communities of a developing country such as Nigeria. To the best of the researcher's knowledge, this paper is one of the first to make such an attempt. Therefore, the qualitative rich data derived from the interview will increase and contribute to the growing literature on citizen or participatory journalism.

\section{METHODS}

This study made use of the qualitative research design following the phenomenological approach described by (Stake, 2013; Braun \& Clarke, 2013). Interviews were conducted among 40 conveniently selected participants. The interview technique was used because few studies exist that explicate the phenomenon of citizen journalism in Nigeria. Thus, a method allowing for sufficient freedom and depth of probing was needed. This method has been shown to permit participants to describe their feelings in their own words and new themes could be followed up as they emerged (Dogari, Apuke, \& Shadrach, 2018). It was also felt necessary to develop a context-based understanding as regards citizen journalism practice in the rural areas of Nigeria. In keeping with the general practice of qualitative research, the participants were promised and given anonymity in order to encourage them to discuss pertinent issues in-depth and detail (Kontagora, Watts, \& Allsop, 2018). For example, the participants were coded as participant $1,23 \ldots 40$.

\section{Participants and Sampling}

Participants were drawn from Ardo Kola, Taraba State in the northeastern region of Nigeria. Ardo Kola is a Local Government Area in Taraba State, Nigeria. Its headquarter is in the town of Sunkani (Apuke \& Apollos, 2017). The selection of this community was based on convenience and proximity to the researchers. A total of 40 participants volunteered to open requests to participate in the research. These participants are characterised as those who use various forms of new media and have an account on social media. Of the 40 participants, $(n=22)$ were male and $(n=18)$ were female. In terms of age range, $(n=23)$ were between the ages of $18-29$ and $(n=16)$ were 30 and above. For educational background, $(n=18)$ had formal education while $(n=22)$ had no formal education but could still communicate in English. So, the researchers used simple English in the interview session, however, at some point the Hausa language which is the predominant language in the North-eastern part of Nigeria was adopted to emphasis on certain issues as well as enable the participants to comprehend fully the questions inquired of them.

\section{Data Collection Procedure}

Data were collected through face-to-face semi-structured interviews, and all interviews were recorded. The Interviews were conducted in the early months of 2019 and lasted for approximately eight weeks to finish. The interviews were semi-structured to ensure consistency while also allowing particular experiences and matters to be explored in larger 
detail. The questions in the interview script were adapted from established research (i.e. Chatora, 2012; Aligwe \& Nwafor, 2017; Apuke, 2016; Alemoh, 2013; Okoro et al., 2013; Salawu, 2011) with appropriate revisions and modifications to suit into the context of this study. To ensure the validity of the interview script, the interview questions were pretested on six $(n=6)$ participants outside the initial sampled participants. For further scrutiny and review of the questions, the researchers consulted two experts in the field of communication. The individual interviews were facilitated by two experienced research assistants who were trained in qualitative research methodology. Before the interview started, the participants signed a consent form.

Each interview lasted for about 20-60 minutes to complete and were recorded and transcribed verbatim. The researchers also took notes which enabled the documentation of the participant's facial expressions such as a frown, head nodding and sighing. The main points were also summarised at the end of each interview to ensure its accuracy and fairness and to allow participants to add to or correct the notes (Kontagora, Watts, \& Allsop, 2018). The participants were asked whether they fully accept and participate in the exercise of citizen journalism, the prospects of citizen journalism as well as the constraints of adopting citizen journalism. They were further asked to comment on how citizen journalism practice could be improved in rural communities in Nigeria. Therefore, the researchers were seeking to demonstrate the prospects and constraints of citizen journalism adoption and practice among rural community dwellers in a developing country such as Nigerian.

\section{Data Analysis}

To examine the qualitative data received from the interview sessions. The six thematic data analysis steps identified by Braun and Clarke (2013:175) were employed. These entail the researchers transcribing the recorded interviews; rereading the transcriptions to identify emerging themes from the recorded data; reviewing the themes; defining the themes; naming the themes, and lastly writing the outcomes. The assistants recruited for this investigation, paid extensive attention to each step, beginning with the careful arranging of the taped interviews. Thenceforth, the transcriptions were attentively reread to identify emerging themes from the recorded information. The findings were then discussed and interpreted thematically along with the results of the existing literature. This technique is consistent with prior studies (Braun \& Clarke, 2006; Parajuli \& Doneys, 2017). So, the themes centred around confirming whether the participants fully accept and participate in the exercise of citizen journalism, the prospects of citizen journalism, the constraints of adopting citizen journalism, and ways in which citizen journalism practice could be improved in rural communities in Nigeria.

\section{RESULTS AND DISCUSSION}

The results section has been organised into four sub-sections. First, demonstrates the acceptance and participation in the practice of citizen journalism among rural dwellers. Second, highlighted the prospects of citizen journalism in rural communities of Nigeria. Third, demonstrates the constraints of adopting citizen journalism in rural communities of Nigeria. Fourth, establishes the ways in which citizen journalism practice could be better encouraged among rural community dwellers in Nigeria. 


\section{The Acceptance and Participation in the Practice of Citizen Journalism among Rural Dwellers}

In response to the first question about the participant's acceptance and participation in the exercise of citizen journalism, it was found that although the entire participants accept citizen journalism practice, only a few of them participated fully in the practice of citizen journalism. They emphasised awareness and acceptance of the practice, yet, do not overcommit themselves to it. This indicates minimum participation of citizen journalism practice in the sampled area. In this respect, one of the interviewees remarked:

Although we have a slower technological advancement, nevertheless the advancement of citizen journalism has been felt in our area. But many of us do not practice citizen journalism and prefer to use our devices to communicate with friends than post breaking news and events [Participant_1].

Some other participants stated that:

At some time, I do engage in citizen journalism practice. I recall a time when a woman gave birth in the street due to lack of adequate medical facility in my community. I immediately captured the event and posted it online so as to draw humanitarian responses. Nevertheless, I do not frequently partake in citizen journalism [Participant_6].

Supporting this view, a participant claimed that:

I am fully cognizant of how citizen journalism works and I completely accept its practice, but this is not fully encouraged and acknowledged in my community. We have this culture of people minding their business which in turn discourages me sometimes from posting certain issues that happen in my community [Participant_18].

Only a few participants mentioned that they fully partake in the practice of citizen journalism. In this respect, a participant acknowledges to be a citizen journalist affirmed that:

Citizen journalism or participatory journalism is indeed a blessing to us because it has permitted me to share my viewpoint with heterogeneous people in my community and beyond. I will boldly say that I frequently engage in citizen journalism and this has been helpful to my audience. For example, there was a period where rape cases in my community were the order of the day, I took it upon myself to research into the issues, got live photos and footages of those caught in the act and posted them so as to create more awareness [Participant_15].

In line with this notion, one of the interviewees commented that:

I have been practising citizen journalism for about 5 years now and I don't regret this practice or its notion. The practice has made me to inform couple of people on the dangers of certain issues in our community and beyond [Participant_22]. 
Additionally, it was found that the few participants who fully practice citizen journalism do so predominantly through their mobile devices using social media such as Facebook, Whatsapp, and Twitter. Overall, the findings suggest a vast acceptance and knowledge of citizen journalism among the sampled population, but a very low practice of it. These results contrast studies which revealed that citizen journalism has impacted a lot on the lives of Nigeria people and that everyone is now a reporter and has the right to air out his view without running to a media house (Apeverga, 2010; Idoko, 2012). The implication of this current study is that although citizen journalism has permitted easy dissemination of stories in split seconds, yet its full practice has not yet been acknowledged in the grassroots areas of Nigeria and only but a few people are willing to partake in the practice of citizen journalism. This outcome is contrary to the evidence which indicates that in Nigeria, a considerable amount of people are now actively participating in citizen journalism; developing different websites and blogs to distribute information (Dare, 2011: 22). The factors discouraging these participants as regards the full practice of citizen journalism will be outlined in the subsequent themes.

\section{The Prospects of Citizen Journalism in Rural Communities of Nigeria}

The entire interviewed participants acknowledged that the prospects of citizen journalism in their community are inevitable. They believed that citizen journalism has provided an avenue for anyone willing to gather and disseminate messages to the rural dwellers and beyond. It has democratised the distribution of information as anyone could instantly report events in their community. The participants generally held the view that the fastness in the dissemination of messages also makes citizen journalism an interesting one. It delivers messages in a flash like the speed of light which in turn attracts an instant reply from the community dwellers. This notion supports the theoretical framework (Democratic participant media theory) of this study which advocates that the people should have free access to the means of communication as against the monopolistic and rigid structure of traditional mass media (Ojobor 2002: 15; McQuail, 1987: 123). In this regard, one of the rural community dwellers commented that:

The use of citizen journalism has helped some of us expose the ills of government in our community. The issues of lack of basic amenities have been constantly reported by some in our community and neighbouring villages. There are a lot of issues being neglected by the mainstream media that volunteered community citizen journalist report and this has made some government officials come to our aid [Participant_20].

In line with these, a considerable amount $(n=31)$ of the interviewed rural dwellers held the notion that citizen journalism and the advent of the new media has assisted them to checkmate the excesses of government officials in their rural communities. They stated instances whereby government-approved projects in the communities and the rural district head embezzle such money. When such cases are reported to the mainstream media, they are most time not aired. However, with the help of information communication gadgets community dwellers have been able to post such issues on Facebook, Twitter, and WhatsApp, which in turn have attracted the attention of the government to act and remedy the situation. This has brought about developments in their community. One of the interviewed community dwellers, reports:

I recall a time when the government approved the renovation of our community high school. The top officials in our community neglected the project and embezzled 
the money. This situation attracted the community's attention and some of us posted the pictures of the debilitated school, which in turn made the government to arrest the officials that embezzled our community allocation. Within two months the government was able to look for capable hands that renovated our high school [Participant_40].

The participants also held the notion that their community which is situated in the north-eastern part of Nigeria has witnessed some attacks from Boko Haram, which is not immediately reported by the mainstream media. However, some of them have been able to report instantly the occurrence of a bomb last and attacks before any media organizations arrive at the destination. This has enabled them to report first-hand information that could attract a humanitarian response. They believed that the mainstream media could alter the reports to favour the government in power. In line with this notion, one of the participants alleges that:

There was a time when our community was attacked and I was an eyewitness. The mainstream media reported that the attack was not a serious one and there should not be much panicking, however, the incident was a serious one that took the lives of many of our community dwellers. Some of us were able to capture the accurate event and post via various social media platforms which in turn attracted the attention of the United States government. As I speak, we now have a barrack in our community and this has reduced the constant attack on us [Participant_38].

Most of the interviewed rural dwellers perceived that the advent of citizen journalism has enhanced their choice of political candidates. Through the posting of a candidate's achievement and lapses by some of the community dwellers, they have been sensitized to the appropriate candidates that could move their community to greater heights. This suggests that citizen journalism promotes grassroots mobilization. In this respect, a community interviewed participant commented that:

\begin{abstract}
Some of our politicians who are representing us in the National assembly have been exposed through the help of some willing citizen journalist in our community. For example, in many occasions, I have posted the underachievement of some of our so-called political leaders. As far as I am concern, citizen journalism has assisted us to checkmate some of these politicians as well as sensitise us on an appropriate candidate to select [Participant_20].
\end{abstract}

Another benefit of citizen journalism highlighted by the interviewed rural community dwellers is in the aspect of health and hygiene promotion. Most of them pointed out that citizen journalism has helped them to keep hygiene and avoid certain practices. For example, during the outbreak of the Ebola and Bird flu virus, the efforts of some of the community dwellers assisted most of them to stay on guard so as to prevent the spread of the virus. In addition, they also claimed that through various post online they have been able to grasp the dangers of HIV and AIDs and have attempted to visit the community health care centre which in turn has reduced the rate of its spread among some of the rural dwellers. Although some of them are not learned, the pictures and videos posted by some learned ones have assisted them to understand the dangers of HIV, Bird Flu, and Ebola. This suggests that citizen journalism's impact could also be felt by both educated and non-educated. Therefore, it should highly be 
recommended among rural dwellers as they are more prone and vulnerable to diseases. In addition, it was found that in contrast to research finding which claims that lack of credibility and authenticity of citizen journalism content is endangering the societal information cycle (Maher, 2005), the participant believes that the content of citizen journalists is credible as it reports first-hand information, unlike the filtered mainstream media information.

Generally, the implication of the above comments suggests that citizen journalism has provided an avenue for community dwellers to gather and disseminate messages to their fellow rural dwellers and beyond. This implies that instead of them waiting for the mainstream media, some of them have been able to inform the public their aspirations and yearning which in turn has brought some development in the community as well as attracted humanitarian response. The outcome of the above comments also suggests that citizen journalism has assisted rural community dwellers to checkmate the excesses of government officials in their communities, which in turn has enhanced their choice of political candidates. With respect to the promotion of a healthy lifestyle in the community settings, it could be deduced that citizen journalism has helped some of the community members to keep hygiene and avoid certain practices. For instance, during outbreaks such as Ebola and Bird flu virus, community dwellers have been sensitised appropriately. Additionally, their knowledge of HIV and AIDs has also been improved due to their exposure to the videos and photos that demonstrate the dangers of HIV and AIDS, suggesting that videos and photo features of citizen journalism is very helpful to rural dwellers as most of them seem not to be learned. The outcome of this study is consistent with Alemoh's (2013) observation which advocates that most of the issues the mainstream media leave out, the citizen journalist easily captures. Events that occur in distant places are now published directly by citizen journalists; making the public to be mindful of certain matters that happen around them. In addition, Educause Learning Initiative (2007) postulates that through blogs, Facebook, and Twitter citizen journalist has disseminated breakthrough information on political oppression, corruption and economic theft in the society and the world at large.

\section{The Constraints of Adopting and Practising Citizen Journalism in Rural Communities}

In this section, the interviewees were asked to outline some of the issues confronting the actualization of citizen journalism practice in their community. A large proportion of the participants reported poverty and power failure as one of the major constraints to the effectiveness of citizen journalism. This notion was also shared by Aligwe and Nwafor (2017) who found that uneven penetration, illiteracy, constant power failure, endemic poverty and systemic corruption as the major threats affecting the effectiveness of citizen journalism in Nigeria. In addition, the participants in this current study also pointed out to the attitude, religious upbringing and customs of some of the community dwellers. For example, most of the married women in the community are confined to their homes due to the religious rules and this affects them from covering events that could assist the public. Furthermore, the custom of not allowing certain events (such as accident scene, rape cases, murder cases, etc.) to the snapped affects the effectiveness of citizen journalism in rural areas. In respect to this view, one of the interviewed participants stated that: 
Poverty and power failure affect most of us from getting good information communication gadgets and even if we do, there are no constant electricity to keep them charged. For the past six weeks, a rainstorm dropped some electric pole wires in our community, resulting in the shutting down of our cell phones and other technological gadgets [Participant_25].

Other challenges that discourage the adoption and practice of citizen journalist was the high level of illiteracy among the rural dwellers. Although some of them engage in citizen journalism, most of them are discouraged due to lack of adequate knowledge to operate modern technological devices. In line with this one of the participants commented that:

The level of illiteracy in our community is so much that most people don't even wish to own a technological device, talk more of practising citizen journalism. Although some of the community dwellers might be willing to partake in citizen journalism, but are highly discouraged because they cannot read nor write, neither are they acquainted with modern technological devices [Participant_6].

Supporting this point of view, another rural dweller stated that:

Although I own a smartphone and sometimes chat with it, but I lack adequate knowledge that will enable me construct better sentences that I could use along the pictures I wish to upload to the public and this sometimes discourages me from frequent reporting of events that could assist my community [Participant_12].

The participants also pointed out the issue of high internet subscription and slow speed in the rural areas as a factor discouraging them to fully harness the effectiveness of citizen journalism. Most of the participants claimed that they run out of data subscription and have only access to $2 \mathrm{G}$ networks. These findings seem to be a problem that also extends to the urban areas of Nigeria, however, it is most glaring in the rural areas because the rural dwellers report having slower internet services compared to urban cities. In a related study carried out in an urban centre in Nigeria, Idoko (2012) discovered the challenges of citizen journalism include; computer illiteracy, difficulty in accessing the internet and high price of 'surfing' the net. This suggests that the high cost of internet subscription impedes the effectiveness of citizen journalism in both rural and urban areas of Nigeria. Therefore, due to the lack of free internet service, anyone who desires to post any event online must buy "data" which is expensive to some due to the economic situation.

Generally, it could be inferred from the above comments that poverty and power failure, the attitude, religious upbringing and customs, high level of illiteracy, high internet subscription and slow speed in the rural areas are factors discouraging the adoption and practice of citizen journalism in rural areas of Nigeria. In line with this, the participants were asked for comments on the ways in which citizen journalism could be promoted and encouraged in their community and beyond.

\section{Ways in Which Citizen Journalism Practice Could Be Better Encouraged among Rural Community Dwellers}

The majority of the interviewed rural dwellers suggests that the government should make efforts to create more job opportunities as well as sponsor the skill work of those who did 
not attend formal education. They stated that although N-power (i.e. Empowering Nigerian Youths for Prosperity) which the government introduced ought to help in reducing poverty, however, the benefits have not reached their community. In this view, they call on government agencies to make development a priority and that doing so will improve the living condition of those in the rural areas, in turn, encourage the use of technological devices that foster citizen journalism. The participants also called on the government to improve power supply in their community. It was observed that most transformers are no longer functioning and some areas have not seen electricity for a long while, thereby deterring the effectiveness of community and citizen journalism. Most of the participants also reported that more orientation as regards the essence of citizen journalism is needed in the rural areas as some of the rural dwellers might not be even conversant with its practices. One of the participants remarked that:

I believe if the government provide work and support our skills, it will encourage us to buy gadgets that will enable us to effectively carry out citizen journalism. Citizen journalism is only effective when you have the technological tool to broadcast breaking news and events [Participant_28].

Another participant commented that:

In my ward, there are only few people that are aware of citizen journalism or even have a gadget that could facilitate its practice. Thus, I strongly recommend orientation [Participant_21].

The participants also recommended that good schools be set up in rural areas just like urban areas, as most of the learned people in their community were opportune to school outside. Due to the lack of good education, many people are not encouraged to study, thereby resulting in a high rate of illiteracy which in turn discourages the adoption and practice of citizen journalism. So, they believe when the level of illiteracy among the rural dwellers is reduced to the barest minimum it will encourage citizen journalism, as many will have the knowledge to operate modern technological devices. The participants also recommended that the issue of high internet subscription and slow speed should be tackled with urgency to encourage rural dweller to partake in effective community and citizen journalism. Internet service providers should reduce the cost of their subscription and extend a $4 \mathrm{G}$ network to rural areas so as to improve the internet speed, which in turn might encourage citizen journalism.

\section{CONCLUSION}

This study aimed at increasing our understanding of citizen journalism practice, with a focus on rural dwellers which has been less well studied. The findings of this study suggest that there are a vast acceptance and knowledge of citizen journalism among rural dwellers in Nigeria, but its adoption and practice is still very minimal. The few participants who fully practice citizen journalism do so predominantly through their mobile devices using social media such as Facebook, WhatsApp, and Twitter. The possible issues that discourage the full adoption and practice of citizen journalism in rural areas are poverty, power failure, their attitude, religious upbringing and customs, high level of illiteracy, high internet subscription and slow speed. These issues could be reduced if the government make efforts to create more job opportunities, sponsor the skill work of those who did not attend formal education, and 
improve power supply in their community. Orientation as regards the essence of citizen journalism is also required to improve the understanding of rural dwellers. In addition, setting up good schools in rural areas could reduce the level of illiteracy and encourage the use of technological devices that might promote community and citizen journalism. Service providers should reduce the cost of their subscription and improve their network speed to $4 \mathrm{G}$ as obtainable in developed areas so as to encourage citizen journalism among rural dwellers.

Conclusively, it could be seen that although the acceptance of citizen journalism is still minimal in rural areas of Nigeria yet, its prospect is inevitable. This implies that citizen journalism provides an avenue for community dwellers to gather and disseminate messages to their fellow rural dwellers with immediacy, and this notion supports the democratic participant media theory which advocates that people should have free access to the means of communication as against the monopolistic and rigid structure of traditional mass media (Ojobor, 2002: 15; McQuail, 1987: 123). Citizen journalism encourages grassroots mobilization. It also assists in the checkmating of the excesses of government officials in rural communities, which in turn enhances their choice of political candidates. It promotes a healthy lifestyle in the community settings, most especially during outbreaks of viruses. These findings also support the theoretical framework of this study which calls for the liberalization of the media for the common good of the people it is meant to serve. It suggests that people should have free access to the means of communication as against the monopolistic and rigid structure of traditional mass media. The theory advocates that media content generation, production, and dissemination should be done by one person to another instead of concentrating on particular top groups. It calls for the media to be a medium of the people, for the people and by the people rather than a medium in the hands of a few monopolistic groups. The theory discards the top-down communication system that involves professionals and commercial driven motive operators who hijack the media for their selfish interest, but agitate for pluralizing and democratize form of access and production of media contents. Therefore, it is pertinent to encourage citizen journalism practice in rural areas, and further studies could explore beyond the use of a single community, more issues confronting rural dwellers as regards the adoption and practice of citizen journalism in developing countries.

\section{REFERENCES}

Alemoh, T. A., \& Ishima, L. (2013). Social media: An emerging conundrum? AFRREV IJAH: An International Journal of Arts and Humanities, 2 (2), 236-253.

Aligwe, H. N., \& Nwafor, K. A. (2017) Citizen journalism and the coverage of the 2015 General Elections in South-East Nigeria: A SWOT Analysis. IDOSR Journal of Arts and Humanities 2 (1): 1-19.

Apuke, O. D. (2016). Information communication technology and citizen journalism in Nigeria: Pros and cons. Higher Education of Social Science, 11 (4), 14-17.

Apuke, O. D., and Apollos, I. N. (2017). Public perception of the role of Facebook usage in a political campaign in Nigeria. Informing Science: International Journal of Community Development \& Management Studies, 1, 85-102.

Bowman, S., \& Willis, C. (2003). We media. How audiences are shaping the future of news and information. The Media Center at The American Press Institute. Retrieved www. hypergene.net/wemedia/. 
Braun, V., \& Clarke, V. (2006). Using thematic analysis in psychology. Qualitative research in psychology, 3(2), 77-101.

Braun, V., \& Clarke, V. (2013). Successful qualitative research: A practical guide for beginners. London: Sage.

Chatora, A. (2012). Encouraging political participation in Africa the potential of social media platforms. Pretoria, South Africa: Institute for Security Studies.

Dare, S. (2011). The rise of citizen journalism in Nigeria - the case of Sahara Reporters. Reuters Institute. https://reutersinstitute.politics.ox.ac.uk/our-research/rise-citizen-journalismnigeria-case-study-sahara-reporters

Dogari, K. A., Apuke, O. D., \& Shadrach, I. (2018). Comfort or conflict? Investigating the attitude and experiences of european football fans in television viewing centers in Nigeria. Global Media Journal, 16 (30), 1-10.

Educause Learning Initiative. (2007). 7 things you should know about citizen journalism. Educause. https://library.educause.edu/resources/2007/11/7-things-you-should-knowabout-citizen-journalism.

Folarin, B. (1998). Theories of mass communication: An introductory text. Lagos: Stirling-Horden Publishers (Nig) Ltd.

Grubisich, T. (2005, October 5). Grassroots journalism: Actual content vs. shining ideal. Online Journalism Review. http://www.ojr.org/p051006/.

Idoko, A. (2012). Citizen journalism; and social media. Makurdi Journal of Communication Research.https://makurdijournal.files.wordpress.com/2014/03/citizen-journalismand-social-media-by-idoko-alice.pdf

Kontagora, H. L., Watts, M., \& Allsop, T. (2018). The management of Nigerian primary school teachers. International Journal of Educational Development, 59, 128-135.

Maher, V. (2005). Citizen journalism is dead. Media in Transition. https://web.archive.org/ web/20060924125946/http://nml.ru.ac.za/maher/?p=6

McQuail, D. (1987). Mass communication theory: An introduction ( $2^{\text {nd }}$ ed). Thousand Oaks, CA: Sage.

Mgbejume, O. (2008). Television-Video Production. In H. Ekwuazi, J. Sokomba \& O. Mgbejume (Eds.) Making the transition from video to celluloid (pp. 47-71) Jos: Motion Picture Academy.

Noor, R. (2017). Citizen journalism vs. mainstream journalism: a study on challenges posed by amateurs. Athens Journal of Mass Media and Communications- 3 (1), 55-76.

Odii, C. (2013). Public perception of the implications of citizen journalism for Nigeria's democracy. International Journal of Research in Arts and Social Sciences, 5, 435-448.

Ojobor, I. (2002). Mass communication theories. In S. Okunna (ed). Teaching mass communication: A multi-dimensional approach. Enugu: New Generation Books.

Okoro, N., Diri, C. T., \& Odii, C. (2013). Citizen journalism in Nigeria: Possibilities and challenges. New Media and Mass Communication, 11, 1-7.

Parajuli, R., \& Doneys, P. (2017). Exploring the role of telemedicine in improving access to healthcare services by women and girls in rural Nepal. Telematics and Informatics, 34 (7), 1166-1176.

Paulussen, S., \& Ugille, P. (2008). User generated content in the newsroom: Professional and organisational constraints on participatory journalism. Westminster Papers in Communication \& Culture, 5 (2), 24-41. 
Salawu, A. (2011). Citizen journalism off-line: The (Nigerian) punch's model. Journal of Communication, 9, 185-196.

Stake, R. E. (2013). Multiple case study analysis. New York: Guilford Press.

Tsegyu, S. (2016). Citizen journalism and election monitoring in Nigeria. Jurnal KomunikasiMalaysian Journal of Communication, 32 (1), 491-517.

United Nations Development Programme. (2010). A baseline readiness assessment of the Nigerian media as a forum for citizen engagement in the 2011 election. UNDP. htp://www.ng.undp. org/dgd/media-report-baseline-survey-october-2010pdf. 